\title{
THE ROLE OF TIME MANAGEMENT SKILLS IN FULFILLING ASSIGNMENTS OF RESEARCH METHODOLOGY SUBJECT OF SENIOR STUDENTS - A CASE STUDY AT TRA VINH UNIVERSITY
}

\author{
Nguyen Thi Ngoc $\operatorname{Van}^{1}$, Truong Thi Thanh Ngan ${ }^{2}$
}

\begin{abstract}
Time becomes a greatly essential factor and time management skill is more important to students' lives, study and especially in Research Methodology subject. Realizing that, this research aims to study the relationship between time management and performance on Research Methodology subject, specifically to find out techniques which students use to fulfil in assignments of this subject. Questionnaires including questions related to students' perspectives on time management skills and the factors affecting the relationship between time management and Research Methodology subject were delivered to sixty senior students. The findings show the roles, as well as the effects of time management on assignment fulfilment, were confirmed. Most of the participants agreed that time management skills played an essential role in their ability to complete assignments of the subject. And the study also provides students with some effective time management techniques for their successful study.
\end{abstract}

Keywords: assignment fulfilment, techniques, time management skills.

\section{INTRODUCTION}

For decades, Orlikowski \& Yates [1] observed that developing global competition,

\footnotetext{
${ }^{1}$ School of Foreign Languages, Tra Vinh University

${ }^{2}$ Student of School of Foreign Languages, Tra Vinh University

Email: ntnvan@tvu.edu.vn

Received date: $26^{\text {th }}$ July 2019; Revised date: $12^{\text {th }} \mathrm{Au}$ gust 2019; Accepted date: $16^{\text {th }}$ May 2020
}

exponential increases in the speed of computerizations, telecommunications, and meeting the command of the availability and immediacy of products and services have played into a resurgence of interest in time and timing.

Most people know the impact of time, and its importance, on our lives but some hardly manage time well because of different influential factors. Britton \& Tesser [2] believed that time management has certain effects on educational achievement. However, a correlation between time management skills and academic accomplishments is equivocal, Swart et al. [3].

The School of Foreign Languages introduces Academic Writing and Research Methodology (RM) for students to get familiar with how to conduct scientific research. From the two subjects, students are equipped with basic knowledge on principles about RM, they can research on their own. However, students could not submit assignments of RM on time due to lack of time management skills, or sometimes that makes students lead to time mismanagement, poor sleep patterns, and increased levels of stress, Hardy [4]. As a result, time management is widely considered a vital factor requiring students to manage their study effectively.

First, the research aims to find out students' perceptions about time management towards RM subject. Then, the factors affecting students in managing time to fulfil the assignments of RM subject are explored. From those factors, some techniques are introduced so that students can use to improve their time 
management skills for successfully fulfilling assignments of this subject.

The research aimed to answer two questions:

- What is the relationship between time management skills and finishing the RM's assignments?

- What techniques are used by students to finish the assignments of RM on time?

\section{LITERATURE REVIEW}

\section{A. Theoretical background}

1) Definition of Time Management: In our modern society, time is considered one of the most priceless resources, time management can be seen as an indispensable skill for both studying and working. As noted by Zampetakis, Bouranta, Moustakis [5], "Broadly speaking, time management refers to activities that imply an effective use of the time that is deemed to facilitate productivity and alleviate stress". In other words, time management is managing our time effectively to improve work productivity. It means that we waste no time to finish the goal but it still fulfils all the tasks fully. As stated by Ahma et al [6] in their study that time management is the principle of any successful event. They also emphasized that "time management is the act or process of planning and exercising conscious control over the amount of time spent on specific activities, especially to increase effectiveness, efficiency or productivity". So, time management is also seen as the art of time arrangement. Time management initiates one of the most regular topics discussed in learning and study, in the courses and plenty of handbooks on study skills. According to Indreicaa, Cazanb, Truţac [7], time management becomes necessary for every student. In line with the statement, MacCann et al. [8] considered that time management is an intimate key to educational attainment. Also, time management is one of the two significant elements relating to the creativity of each person, Zampetakis et al. [6].
Specifically time attitude, time management includes daily planning and confidence in long-range planning that have an interaction toward individual creativity. Time management is only an important factor of success but a difficult skill. To have good time management skills is not a straightforward process for everyone, especially for students.

2) Importance of time management: According to Mancini [9], efficient time management can decrease pressure at work. Moreover, it has a strong effect on daily life, so in people's learning, time management is not necessary. Proper time management is a critical factor to success in the college study environment. Similarly, Van de Meer et al. [10] described that time management has a strong effect on the transition from high school to the university environment. In high school education, teacher and onclass attendance have a closed relationship to students' learning outcomes but in university, their study results come from themselves primarily. Students spend more time selfstudying at home or at the library for reference materials to support the study than sitting in classrooms. Their academic subjects' results come from their hard-working efforts. Therefore, students have to plan their time to balance their study and life.

3) Factors affecting time management:

Time management skills are the necessary skills to be obtained. Any person can train and use those skills, however, being a successful time manager is not easy because it can be affected by various factors, both external and internal. External factors include task providers, unexpected incidents, tools... and internal ones are expected to be (planning skill, work division, work strategically). In a study by Ozsoy [11], he explored that gender and work do not affect time management skills. It means that whether a person is male or female, or what his job does not appear to relate to his time management skills.

Besides, advice from counsellors plays an essential role which decides the efficiency 
rate of time management. The instructor gives assignments or tasks and they set up the time for each assignment. In some cases, instructors provide appropriative strategies for the given tasks. However, how time is spent depends on task receivers' attitudes such as going to the library regularly and keeping the regular speed on working, Swart et al. [3]. Additionally, time managers' attitude is the cause leading to procrastination. According to Mancini [9], procrastination is defined as the main cause of work delay. It comes from many different roots but most of them are internal factors. Particularly, he shows eight factors. First, one of the common reasons, task receivers think that the task is difficult and vast and they do not want to do it. They think the task is complex and overloading in comparison with their ability. Next, if doing a task without planning, it will affect the result of the task seriously. A plan with an instructional role should keep things on track. Besides that, setting a goal is a compulsory step to avoid wandering. It is important to determine what the goal of the task is and how to approach it. Sometimes, in the journey to attain the goal, we have to adapt to complete each small part. Perhaps our change will be better or worse but we can try and do it right one more time. Being afraid of changing and making mistakes is not a quality of successful time-manager. Then, people usually want to complete many things but they pay insufficient attention to time. In some cases, a lot of work and a little time will make people feel stressed. They are under pressure of being an excellent person, so they undertake a lot of work and try to solve them as soon as possible. After a long period, cramming will lead to excessive stress and have a bad effect on both their work and personal life. It means that their time management is unsuccessful.

4) Techniques and tools to improve time management: Managing time is considered a professional ability. People can improve their ability at any time if they want to get a high result in their job. From a similar viewpoint, it was indicated that time management skills can be trained. There is an interconnection between time management and academic achievement. Accordingly, using time managing training programs could practically result in improving academic achievement, especially for poor time managers There are several techniques as tools to improve time management skills but each person needs to find their time management style (Mancini [9]). As Mancini's thoughts, every individual is unique, so there is no fixed time management style for all. For that reason, basing on the feature of the job, characteristic, living environment, etc., each one needs to find their time management style to attain effective achievement.

For example, Mancini [9] mentioned procrastination as a hindering factor. Besides, he revealed not only eight factors leading to procrastination but also solutions for the factors. According to him, each factor leading to procrastination has each strategy to solve it. For example, if the task seems massive, you can divide into small parts and complete one by one. Depending on the task and its difficulties, it will have solutions to fit each one.

According to Chase et al. [12], one of the notable basis to be a successful time manager is learning how to refuse trivial doings and set important things as a priority. To arranging the affairs, we need a todo list. To-do list is used for arranging the affair in a day, a week, a month, a year or even several years. Relying on Alexander and Dobson [13], they illustrated some factors can make a successful to-do list. One of these factors is that arrangers create a schedule for each day and maintain it, making sure that the time in the schedule is real-time and enough to solve the work. Arrangers should not cover many items in a day. It will lead to procrastination - a difficult matter to solve in time management. 


\section{B. Related studies}

Britton \& Tesser [2] carried out a study to analyze the effectiveness of time management in the class of students at the Institute for Behavioral Research and Department of Psychology University of Georgia. Ninety college students completed a time-management questionnaire in 1983, and their high school Scholastic Aptitude Test (SAT) scores were got from college records. Principal-components analysis of the 35item time-management instrument revealed 3 components. 4 years later, each student's cumulative grade point average was obtained from college records. The analysis showed that time management was a significant predictor of cumulative grade point average and accounted for more variance than did SAT scores. It is concluded that time-management practices may influence college achievement. Compared to this "Time management skills on assignment fulfilment of RM subject", the final result is also similar and time management affects students' achievement in general.

In a study in 2009, Swart et al. [14] researched whether time management skill affects the academic success of African engineering students or not. The research used the imperial study with incorporated an expost-facto study involving experimental and exploratory design using descriptive statistic. The results of this research indicated that there was no statistically significant connection between time management skills and the academic achievement of African engineering students. However, authors gave some effective tools (eight tools in particular) for students to improve time management.

In the study of by Adams and Blair [15], the self-reported time management behaviours of undergraduate engineering students using the Time Management Behavior Scale was examined. The research used analysis of correlation, regression, and model reduction to attempt to determine aspects of time management the students practised, time management behaviours strongly associated with higher grades within the program, and whether or not those students who selfidentified with specific time management behaviours achieved better grades in the program. The findings of the research showed that students' perceived control of time was the factor that correlated significantly with cumulative grade point average and it was found that time management behaviours were not significantly different across gender, age, entry qualification, and time already spent in the program. However, the research also found many students recognized that they found it difficult to have a balance between their studies and daily lives.

Besides, Razali et al. [16] conducted a study to determine the relationship between the time management and academic achievement of the students. The research used questionnaires to find out the result. The result found that all the time management behaviours are significantly positively related to academic achievement of students although the relationship is weak. Meanwhile, time management is very important and it may affect an individual's overall performance and achievements. Three factors associated with time management which can be classified as time planning, time attitudes and time wastage were discovered. The final result also indicated that there was no significant difference between time management behaviours and gender and races and time planning is the most significant correlated factor to academic achievement.

Finally, one study of GaYef et al. [17] was conducted in 2017 to determine the relationship between the time management skills of students and their academic achievement and to evaluate the differences between whether students' time management and sociodemographic characteristics. It was performed with 341 students by questionnaires and analyzed by SPSS 17.0 and finally showed that there was no significant difference between stu- 
dents' time management subscales means scores and academic success according to status, grades, parents and programs.

\section{METHODOLOGY}

The research was examined to explore the relationship between time management and RM subject and discover techniques which students use to finish tasks assigned by teachers of RMs on time.

The participants of the research were 60 senior students who study English major. They have finished the main subjects of the training program of Tra Vinh University for English major students. They also have just finished Research Methodology subject in the previous semester. Although they come from the same class, they attend different Research Methodology class with different teachers.

The research instrument is a questionnaire. The questionnaire has 15 items divided into three main parts: students' perception of time management, factors affecting students in managing time to fulfil assignments of Research Methodology subject and techniques that students can use to improve time management on fulfilment assignment of Research Methodology subject. The questions from 01 to 05 are a five Likert-type scale and the remaining questions are multiple responses.

Researchers created a questionnaire including 15 items in total. The questionnaires were given to 60 senior English majors who were the main participants of this study. The researchers explained the questionnaire to the participants and went back to collect the questionnaires. It took us around 20 minutes.

The questionnaire of the research had two types of questions and the researcher used IBM SPSS statistics 20 to analyze the data. After that, each question was analyzed to get descriptive statistics of each one. The figures from descriptive statistics became meaningful data toward this research

\section{DATA ANALYSIS}

This analysis began with the students' perception of time management. The authors want to identify whether students think that time management has any relationship to RM subject. There are four questions. They were designed to learn how the students know about time management.

First, the importance of time management skill was answered. Besides, in their opinion, teachers or students will need time management skill in a university environment. Simultaneously, from the questionnaire, the authors also found out the level of students' time management skill.

Table 1: The overall mean of students' perception towards time management

\begin{tabular}{|l|c|c|c|c|c|}
\hline & $\mathrm{N}$ & Minimum & Maximum & Mean & $\begin{array}{c}\text { Std. } \\
\text { Deviation }\end{array}$ \\
\hline $\begin{array}{l}\text { Perception } \\
\text { mean }\end{array}$ & 60 & 3.00 & 4.40 & 3.8067 & .34732 \\
\hline $\begin{array}{l}\text { Valid N } \\
\text { (listwise) }\end{array}$ & 60 & & & & \\
\hline
\end{tabular}

(Source: Authors' survey, 2019)

Table 1 represents the overall mean of students' perception of time management. The overall mean is higher than the average mean portion $(\mathrm{M}=3.8, \mathrm{SD}=0.347)$. It means that students are aware of time management although their awareness in this phrase is not deep. Firstly, in these factors, most of the participants agreed that they could help themselves to improve time management skill. Secondly, they also accepted the importance of time management. Lastly, the participants thought they can use their time well. From the analyses above, the researcher believes that none of the participants can deny the inportance of time management skill because this skill plays a necessary role and contributes to their success in life. Apparently, doing self-improvement plays a significant role in the students' perception toward fulfill- 
ing the assignments of the Research Methodology course. This result was relatively close to the studies of Nadinloy et al. [2], Adams et al. [15] and Razali et al. [16] that the time management skill played an important role in students' academic achievement. According to three studies, most students agreed that time management skill has a stable position in their study careers. However, this research focused on the especially subject of the course- Research Methodology. Therefore, being compared to three above research, this research was a new topic to be found out with a specific subject- RM subject, not academic achievement generally. Moreover, it was also completely different with the final results of the research Swart et al. [14]. In the study of Swart et al. [14], there is no relation between time management skills and academic achievement, but in this research, there is a relationship between time management and academic of RM subject.

In the first item of Table 2, the importance of time management skill is surveyed. It is obviously seen that most of the participants agree that time management skill is an essential skill $(\mathrm{M}=4.63, \mathrm{SD}=0.517)$. However, numerous of them admit that time management skill is not their strong skill.

Looking at three next items in Table 4.2, those items relate to candidates who help students improve time management skill. Among those candidates, "yourself" reaches the highest position in comparison with the two remaining ones - "family" and "teacher" $(\mathrm{M}=4.7, \mathrm{SD}=0.645)$. Firstly, according to the findings of this study, the participants thought arranging time was an extremely important factor in the Research Methodology subject. Secondly, the responsibilities of each member in their group also influence the completion of assignments of the Research Methodology course. Thirdly, assignments of other subjects contribute to the pressure to fulfil the assignment of Research Methodology subject. Sometimes, they fail to deal with the pressure of completing other assign- ments.

Findings of this research are both in line with and contradict to other previous studies of Adams et al. [15] and Razali et al. [16]. Similar to studies Adams et al. [15], Razali et al. [16], this research also found that there was no relation between the time management with races, genders or even ages of students. Meanwhile, the research [16] showed three factors affecting students' academic achievement, time-planning, time attitudes and time wastage. Among those factors, time planning shared a similarity with the result of this research was that "time arranging". The results of this research had responsibilities of members, pressure from other subjects' assignments and others and families which are different from Razali et al. [16]. Likewise, the research of Adams et al. [15] also concluded that the students' perceived control of the time factor was generally related to the cumulative average grades of students.

From Table 3, arranging time has a strong effect on assignments fulfilment of Research Methodology subject. It has the highest percentage at $32.6 \%$ while the responsibilities of each member in groups and pressure of assignments of other subjects indicate lower rates at $28.4 \%$ and $25.5 \%$, respectively.

Some techniques that can help students improve time management to fulfil the assignments of Research Methodology subject were suggested. Foremost, planning and setting goals for all affairs are indispensable techniques. The two techniques are a detailed plan as well as a strategy for each affair. The participants choosing these techniques believe that goal is an important point in the whole process of doing anything. Because of that, planning and setting goals play the role of a guiding light. Students have to try to approach the goal as soon as possible.

From a different perspective, a group of participant supports "choosing the time slot" item. This phrase means that students choose a time slot in the day that they can work 
Table 2: Descriptive Statistics of students' perception of time management

\begin{tabular}{|l|c|c|c|c|c|}
\hline & $\mathrm{N}$ & Minimum & Maximum & Mean & Std. Deviation \\
\hline Time management is an important skill & 60 & 3.00 & 5.00 & 4.6333 & .51967 \\
\hline Your time management is good & 60 & 2.00 & 5.00 & 3.0667 & .86095 \\
\hline You can help yourself to improve time management skill & 60 & 2.00 & 5.00 & 4.7000 & .64572 \\
\hline Your family can help you to improve time management skill & 60 & 2.00 & 5.00 & 3.2167 & .78312 \\
\hline Your teachers can help you to improve time management skill & 60 & 2.00 & 5.00 & 3.4167 & .78744 \\
\hline Valid N (listwise) & 60 & & & & \\
\hline
\end{tabular}

(Source: Authors' survey, 2019)

Table 3: The factors affecting students in managing time to fulfil the assignments of Research Methodology subject

\begin{tabular}{|c|l|c|c|c|}
\hline \multicolumn{2}{|c|}{} & \multicolumn{2}{|c|}{ Responses } & $\begin{array}{c}\text { Percent of } \\
\text { Cases }\end{array}$ \\
\cline { 3 - 5 } & N & Percent & \\
\hline \multirow{5}{*}{ Factors } & Arranging time & 46 & $32.6 \%$ & $76.7 \%$ \\
\cline { 2 - 5 } & $\begin{array}{l}\text { Responsibilities of each } \\
\text { member in groups }\end{array}$ & 40 & $28.4 \%$ & $66.7 \%$ \\
\cline { 2 - 5 } & $\begin{array}{l}\text { Pressure of assignments } \\
\text { of other subjects }\end{array}$ & 36 & $25.5 \%$ & $60.0 \%$ \\
\cline { 2 - 5 } & $\begin{array}{l}\text { Influences from family } \\
\text { and other relations }\end{array}$ & 19 & $13.5 \%$ & $31.7 \%$ \\
\hline
\end{tabular}

(Source: Authors' survey, 2019)

effectively. An appropriate time slot can increase work productivity. For instance, many people's productivity is increased when they work in the morning but in the afternoon or the evening, they usually procrastinate the task.

Another technique is promising a reward or a gift for themselves. Participants support the opinion that students promise a reward for themselves when they reach settle goals. Most of people love gifts or rewards, so this will motivate them to try to do their best to get a better result. All of those factors above were different from the research by Gayef et al. [17], and are also the new ways for students to succeed in their assignment during the Research Methodology subject.

Importantly, the research Gayef et al. [17] mentioned the most important techniques to be good at time management was the awareness of students' attitudes, planning and thinking behaviours. Similarly, this study suggested that arranging and carrying out the affairs based on priority order, planning and setting goal for all affairs are the most suitable solution for most university students.

\section{TECHNIQUES THAT CAN HELP STUDENTS TO IMPROVE TIME MANAGEMENT}

Table 4.4 describes some techniques that can help the students improve time management on fulfilment the assignment of Research Methodology subject. The technique holding the highest proportion is planning and setting goals for all affairs (23.6\%). Similarly, arranging and carrying out affairs based on priority order is the second highest one, making up $22.3 \%$ of participants' choices. Besides, the three techniques having a quite close rate are creating a schedule for the whole week, sketching out a to-do list and feasible time for each affair and choosing the time slot in the day that can achieve high effective working productivity $(16.9 \%, 16.2 \%$ and $14.2 \%$, respectively). Lastly, promising a reward/ a gift for yourself when fulfilling the deadline is the lowest item (6.8\%).

The third and fourth position in the techniques is creating a schedule and sketching out the to-do list. Creating a schedule can be seen as a general plan. It means that students 
make a plan for the whole week. After having a plan for a week, sketching out a to-do list is a needful step. Sketching out the list helps students remember what they will do in a day and control all the things in the day easily.

\section{CONCLUSION AND RECOMMENDATIONS}

\section{A. Conclusion}

This research has aims to discover the relationship of time management skills in fulfil assignments of RMs and some techniques help students summit tasks on time. The participants are 60 last-year English majors at Tra Vinh University. The 15 item- questionnaires were used to collect data.

Findings from this research both confirmed the results found by other researchers and introduced some interesting knowledge to the area of research. First of all, among the factors affecting fulfilment assignments of Research Methodology subject, arranging time is the most common factor. The responsibility of each group member plays a vital role in the whole process of the course. Besides, the study also revealed that assignments of other subjects also directly effect on fulfilment assignments of Research Methodology subject. After determining those factors, the researchers believed that some techniques such as planning and setting goals for all affairs, arranging and carrying out the affairs basing on priority orders, creating a schedule for the whole week, sketching out to-do lists and feasible time for each affair, choosing the time slot in the day not only can help students improve time management toward the Research Methodology subject but also beyond that area.

\section{B. Implications and recommendations of the study}

This study is dedicated to students who will study the Research Methodology subject. It can be seen from the findings of this study that time management skill not only affects students' performance in the RM subject but also helps students achieve good results in this subject. First, students need to determine the factors hindering the process of learning this subject. After identifying the problem, students need to solve the problem as soon as possible and thoroughly. Another important step, students need to know how to manage their time. Moreover, it is necessary to arrange a time for each task, each problem to ensure that they do not affect each other, in particular, do not affect their learning.

Besides, students should apply some techniques that help them improve their time management skills to complete assignments on time which were given in the questionnaires and discussed. The students attending this research agreed that the techniques are effective to them, so the students have learnt and will learn Research Methodology subject completely can use it in their research in the future. Finally, if students are not able to train their time management skills by themselves, students can join skill clubs or time management courses. It will be a good environment for students to practice and develop their time management skills as well as become a skilful time manager in their study and life.

To teachers, they had better have specific teaching plans which are suitable for each group of class of this subject. Due to capacities of students in the groups and conditions of classrooms, teachers as the planners create suitable and flexible activities and assignments to help them improve and complete their assignments in time and have better time-management skills. At the same time, teachers should take careful consideration of the useful techniques which are suitable for each of the students.

It could be better if future research will be focused on the relationship between time management skills and students' study achievement instead of only one subject, Research Methodology. Specifically, students could apply time-management skills on their study achievement better and they will be 
Table 4: Techniques that can help students to improve time management

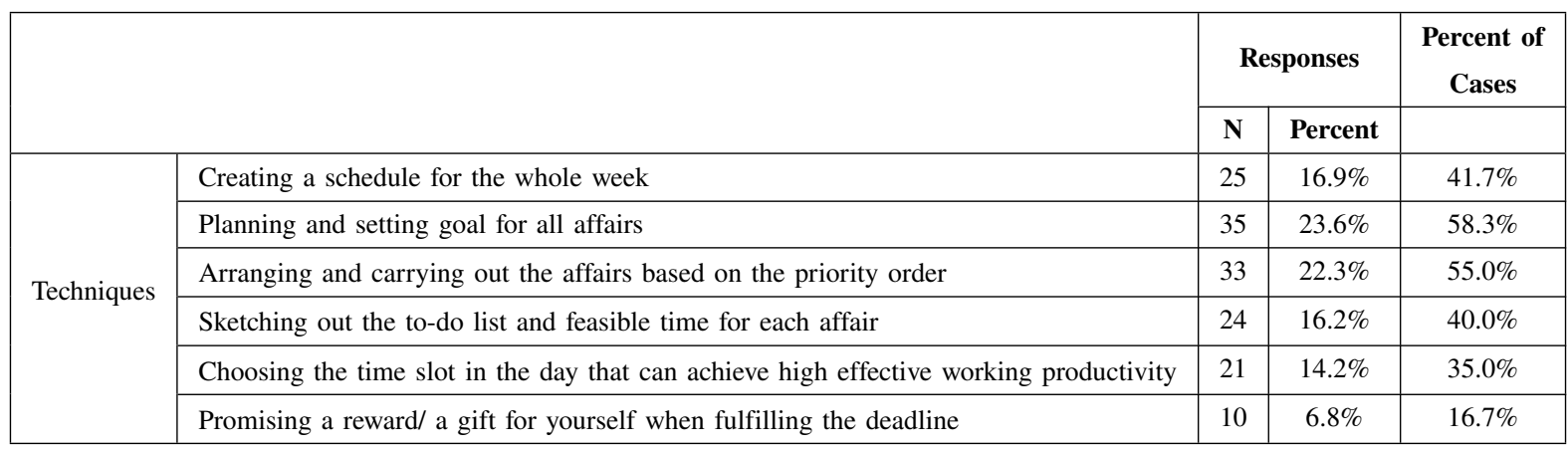

(Source: Authors' survey, 2019)

able to adjust their study abilities to each subject suitably or make them adapt with studying environment. Likewise, further research could be conducted on the relationship between time-management skills and students' future employabilities to make students have a clearer on job-orientation at university.

\section{REFERENCES}

[1] Orlikowski W J, Yates J. It's about time: Temporal structuring in organizations. Organization Science. 2002;16(3):684-700.

[2] Britton B K, Tesser A. Effects of time-management practices on college grades. Journal of educational psychology. 1991;83(3):405-410.

[3] Nadinloyi K B, Hajloo N, Garamaleki N S, Sadeghi H. The study efficacy of time management training on increase academic time management of students. Procedia-Social and Behavioral Sciences. 2013;84:134-138.

[4] Hardy L. Helping students de-stress. Education Digest. 2003;68(9):10-17.

[5] Zampetakis L A, Bouranta N, Moustakis V S. On the relationship between individual creativity and time management. Thinking skills and creativity. 2010;5(1):23-32.

[6] Ahmad N L, Yusuf A N M, Shobri N D M, Wahab S. The relationship between time management and job performance in event management. Procedia-Social and Behavioral Sciences. 2012;65:937-941.

[7] Indreica E S, Cazan A M, Truta C. Effects of learning styles and time management on academic achievement. Procedia-Social and Behavioral Sciences. 2011;30:1096-1102.

[8] MacCann C, Fogarty G J, Roberts R D. Strategies for success in education: Time management is more important for part-time than full-time community college students. Learning and Individual Differences. 2012;22(5):618-623.
[9] Mancini M. Time management. The McGraw-Hill Companies; 2003.

[10] Van der Meer J, Jansen E, Torenbeek M. It's almost a mindset that teachers need to change: first-year students' need to be inducted into time management. Studies in Higher Education. 2010;35(7):777-791.

[11] Ozsoy D. University students' in the Examination of Skills and Attitudes of Time Management. ProcediaSocial and Behavioral Sciences. 2014;152:358-361.

[12] Chase J A D, Topp R, Smith C E, Cohen M Z, Fahrenwald N, Zerwic J J, et al. Time management strategies for research productivity. Western Journal of Nursing Research. 2013;35(2):155-176.

[13] Alexander R, Dobson M S. Real-world time management. American Management Association. EPA/444/4-89-001. U.S. Environ. Prot. Agency, Washington, D.C; 2009.

[14] Swart A J, Lombard K, de Jager H. Exploring the relationship between time management skills and the academic achievement of African engineering students-a case study. European Journal of Engineering Education. 2010;35(1):79-89.

[15] Adams R V, Blair E. Impact of Time Management Behavior on Undergraduate Engineering Students' performance. Sage Open Original Journal-Creative Common CCBY. 2019;9(2):1-11.

[16] Razali S N A M et al. Impact of Time Management on Students' Academic Achievement. Journal of Physics. 2017;995(1):12-42.

[17] Gayef A et al. Relationship between time management skills and academic achievement of the students in Vocational School of Health Services. Journal of Education Psychology. 2017;20(2):247-257. 